
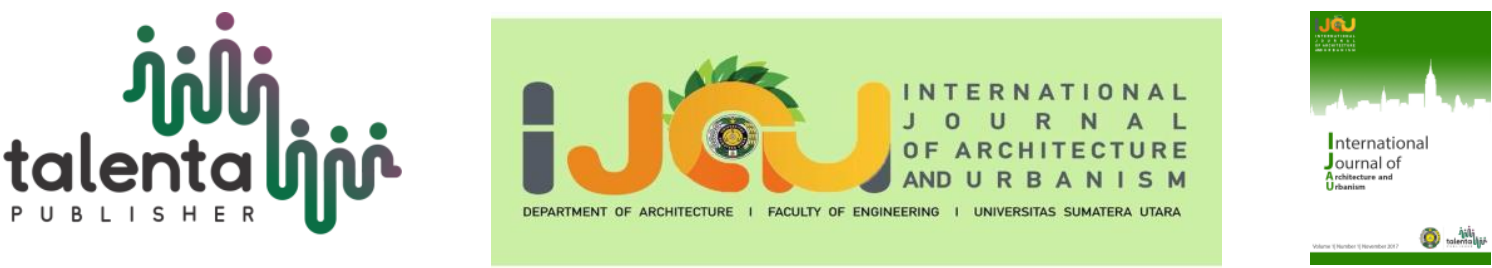

\title{
Security And Safety Evaluation of Motorcycle Parking Mall Podomoro City
}

\author{
Novrial $^{1}$, Gloria Octavia ${ }^{*}$ \\ ${ }^{I}$ Departement of Architecture, Faculty of Engineering, Universitas Sumatera Utara, Medan, Indonesia
}

\begin{abstract}
So many cases of crime have occurred in the parking area. Because this causes many losses, ways are needed to avoid it happening again. One of the efforts that can be done in preventing the occurrence of crime in the parking area is by applying security aspects with the concept of Crime Prevention Through Environmental Design (CPTED) and applying safety aspects that examine security aspects in preventing crime in the environment of human activities in a design approach. Environmental and safety aspects. In this study, the method used is descriptive qualitative to obtain factual and systematic data. The data is processed using the AHP (Analytical Hierarchy Process) method with the help of software, namely Super Decision, to get the value of each CPTED component for motorcycle parking facilities. The value of the study of applying the CPTED concept theory for security and safety aspects in the Podomoro Mall motorcycle parking area shows that the elements of the CPTED concept and safety aspects in the motorcycle parking area have not been fully implemented. However, overall security and safety in this parking area are guaranteed because almost all the variables available at this location already meet existing standards. The riders feel safe and secure when they are in this parking area even though some aspects are not met. It could be improved would be much better. The results of this study are expected to be helpful in the field of architecture, especially in crime.
\end{abstract}

Keywords: cpted, mall, parking, safety, security.

Received 16 October 2021 | Revised 17 November 2021 | Accepted 19 November 2021

\section{Introduction}

Evaluation is considering something, things, or symptoms by considering various factors called Value Judgment. So from the meaning of the conclusion above, evaluation is the process of determining the value of a thing or object based on specific references to determine specific goals.

The word security is a noun form of the adjective safe, which comes from security, which means free from danger. Meanwhile, the word safety comes from the word safety, which means a condition of danger, risk, or injury.

\footnotetext{
*Corresponding author at: Department of Architecture, Faculty of Engineering, Universitas Sumatera Utara, Perpustakaan st. Building J07, Medan, 20155, Indonesia

E-mail address: gloriaoctavia69@gmail.com
}

Copyright (c) 2021 Published by Talenta Publisher, 
As one of the third most significant cities in Indonesia, Medan has reasonably rapid growth and regional development. Due to the speedy population growth. The development and growth of traffic on the highway also continue to increase every year due to the overall development of the city.

The growth of multi-story buildings is also overgrowing. Construction is an essential requirement in Medan to accommodate business activities, and the example is a mall. The mall is one type of shopping center that is architecturally a closed building with regular walking paths in which the manager provides small shops for selling in this mall. Due to the broad architectural form of the building, generally, a mall consists of three floors.

Various supporting needs have also begun to increase, including parking to support the main activities in business buildings. Failure to provide adequate parking facilities can cause a jam and can even reduce the access value of a building. The appropriate parking capacity and properly used parking locations will certainly not cause traffic obstruction. However, the reality is not like that. In practice, we still see weaknesses in parking area design. Irresponsible people can exploit weaknesses in parking area design to do things that can be detrimental. So many crime cases have occurred in parking areas in Indonesia.

With so many losses caused by crimes and accidents in the parking area, a way is needed to avoid such incidents from happening again. One way that can be done is by implementing the security aspect with the concept of Crime Prevention Through Environmental Design (CPTED) and implementing the safety aspect that examines security aspects in preventing crime in the motorcycle parking area in an environmental design approach and safety aspects.

Because there are still weaknesses in architectural design, it is the author's consideration to do this research, so it is necessary to study the parking design. This study will discuss the application of security and safety aspects in the parking area of the Podomoro City Mall motorcycle.

\section{Literature Review}

\subsection{Conceptual Definition}

According to The Great Dictionary of the Indonesian Language (KBBI), the meaning of the word evaluation is assessment. If it is related to buildings, building security is a condition free from risks that threaten the safety of human life in it and building assets that are inside the building as a result of a crime. The word "safety" comes from the Cambridge English Dictionary, namely the word "safety" (n) which means "a state in which or a place where you are safe and not in danger or at risk." safe and not in danger or risk. So the conclusion is that the word "safe" means being free from danger, calamity, disaster; avoid danger, calamity, disaster; do not get distracted, and damage. If it is related to a building, the safety of the building in 
question is a condition free from risks that threaten the safety of human life in the building caused by the building itself.

\subsection{Parking}

According to Article 1 Number 22 the Year 2009 [1], the definition of parking concerning Road Traffic and Transportation reads: "Parking is a state of a vehicle stopping or not moving for a while, and the driver is abandoned." The traffic regulation book (1998) [2], explaining that the notion of parking is a place to stop a vehicle for a long or short period depending on the vehicle and its needs. According to the Decree of the Minister of Transportation No. 4 Article 1 of 1994 , parking is a stationary vehicle that is not temporary.

\subsection{Security Aspects with the CPTED Concept}

Crime Prevention Through Environmental Design (CPTED) is not a new concept. C. Ray Jeffery coined this phrase in 1971. According to C. Ray Jeffrey, CPTED is a built environment design that effectively aims to reduce the incidence of crime. However, a significant contributor to the CPTED concept is the famous criminologist Timothy D. Crowe. His book, Crime Prevention Through Environmental Design [3], is a significant resource for crime prevention practitioners in the security industry to help them better understand the relationship between design and human behavior. According to Marzbali (2016), Crime Prevention Through Environmental Design, commonly called CPTED, is an effective and appropriate design of the built environment that aims to reduce the fear and incidence of crime [4]. CPTED promotes active, mixed-use developments and works best when active community participation is recruited [5]. CPTED is now considered one of the most advanced and effective methods, in some cases, in preventing crime within the living spaces [3]. CPTED is a proactive approach to manipulating the physical environment and producing the desired behavior from reduced criminal activity and reducing fear of crime. Meanwhile, the definition of CPTED, according to the National Crime Prevention Institute (NCPI), is a good and practical design in the built environment that aims to reduce the risk of crime, improve quality of life and increase profitability. Based on the description above, the conclusion is better to regulate humans and the physical environment to produce better results in the future. In a residential environment, profitability is defined as protection from property values and improved conditions. In a commercial environment, profitability is defined as economic improvement, job vacancies, and anything profitable.

The CPTED concept is part of a holistic approach to security; it is readily incorporated into physical security measures to reduce the likelihood of crime occurring and help reduce fear of crime. CPTED is not the only answer to preventing crime and other illegal activity; on the contrary, it is an approach that can be combined with other components of the entire security 
process. Katyal (2002) [6] says that an empirical study of robbers shows that surveillance is a predictive measure of crime rates in the area.

According to Cozens (2005) [7], this CPTED theory is based on the argument that most crime incidents are supported by opportunities created by the environment's design. Meanwhile, the CPTED approach is based on reducing the chance of this happening, which aims to manipulate the built environment to influence human behavior, reducing the incidence of these crimes. As in the CPTED concept, environmental design is rooted in the design of the relationship between the environment and humans. The term environment includes the people and the physical and social conditions around them.

According to Moffat (1983), there are six basic principles of CPTED, that is (1) Territoriality, (2) Surveillance, (3) Access Control, (4) Target Hardening, (5) Image and Management, (6) Activity Support.

In the book 21st Century Security and CPTED, Atlas (2008) explains that CPTED is a concept that focuses on: (1) People's behavior is related to their physical environment, some locations seem to provide an opening for crime to be committed, and others do not, (2) Physical environment, the physical condition of the environment can be manipulated to produce a behavior that can reduce the incidence of crime, for example, by providing a fence.

Randall I. Atlas, in his book 21st Century Security and CPTED [8], states that the goal of designing a safe parking area is to create an atmosphere that makes criminals feel watched and increases the chance that they will run into trouble. To achieve this, it is necessary to apply the CPTED concept. Atlas (2008) says there are several detailed aspects of recommendations for the use of the CPTED concept; these aspects are related to the six fundamental principles of CPTED previously mentioned, that is: (1) Perimeter Control, (2) Landscaping and Access Point, (3) CCTV and Surveillance, (4) Graphics and Wayfinding, (5) Lighting, (6) Mixed and Multiple Uses, (7) Security Management.

CPTED uses a natural approach by changing the physical environment or buildings to reduce the risk (Tseng et al., 2004) [9]. It is necessary to conduct a Security Audit on a building to formulate appropriate strategies for building security protection by summarizing and developing various past criminal incidents and environmental profiles assisted by local law enforcement (Smith, 1996) [10]. 


\subsection{Safety Aspects according to Chrest (1986)}

According to Chrest (1986) [11], considerations related to parking area safety aspects that must avoid the possibility of accidents are: (1) Tripping and Slipping, (2) Head Knockers and Other Projectiles, (3) Vehicular and Pedestrian Barriers, (4) Vehicular and Pedestrian Conflicts.

According to the IBC [12] General String, based on the number of types of car heights, a retaining wall in the form of a concrete wall with a height of $68.5 \mathrm{~cm}$ (27 inches) will protect $96 \%$ of vehicle types.

The things that must be considered in designing pedestrians according to the Essex County Council (2009) [13] are as follows: (1) Pedestrian paths should be designed adjacent to emergency stairs/lifts, (2) Pedestrian paths need to be placed on special lanes adjacent to vehicle entrances/exits. (3) Different levels of pedestrian access floors must be separated from the entrance and exit of vehicles. (4) The laying of roads for pedestrians must be visible and easily found by pedestrians to encourage pedestrians to walk on them and reduce the possibility of conflicts between pedestrians and vehicles.

\subsection{Analytical Hierarchy Process Method}

Analytical Hierarchy Process (AHP) is a decision support model developed by Thomas L. Saaty [14]. This decision support model will describe a complex multi-factor or multi-criteria problem into a hierarchy, which according to Saaty, this hierarchy is defined as a representation of a complex problem in a multi-level structure where the first level is the goal, followed by the factor level, criteria, and sub-criteria down to the last level of alternatives. With this hierarchy, existing problems can be broken down into groups which will then be arranged into a hierarchical form to appear more systematic and structured.

Analytical Hierarchy Process (AHP) is a decision-seeking method that produces rational decision results. This rational decision is defined as the best decision the decision owner wants to achieve. The main thing about rational decisions is that criteria and alternatives lead to desires based on existing sources. In making a decision, the authors carry out several stages, that is (1) Intelligent, (2) Modeling, (3) Choice.

The AHP method is often used as a problem-solving method because it is as follows: (1) Taking into account the validity up to the tolerance limit for the inconsistency of various criteria and alternatives chosen by the decision-maker. Take into account the durability of the output sensitivity analysis of decision making. (2) The structure is hierarchical due to the selected criteria to the deepest sub-criteria. 


\section{Methodology}

\subsection{Research Area}

The research location is right in the downtown area of Medan at the intersection located on Jalan Putri Hijau, namely Delipark Podomoro City. Because it is in the city center, the traffic in this mall area is quite dense. In the area around this mall, there are facilities such as hotels, independent fields, Samsat, and a deli river which has become an icon of Medan. North limits the research area: Guru Patimpus street, East: Deli River, South: Capital Building, West: Putri Hijau Street

\subsection{Data analysis method}

The data analysis was obtained by using quantitative and qualitative approaches. Biological data obtained from field observation is to recap the list of physical elements of the research variables and record the list of physical elements with the security aspect variable inspection form and safety aspect that has been provided.

After recapitulating and recording the list of variable elements during field observations, then to process the variable element list data, the AHP (Analytical Hierarchy Process) method is used to obtain the level of importance of the variables. This AHP method uses computer software, namely Super Decision. This method uses this software to obtain weighted values for each variable by arranging a pairwise comparison hierarchy. This hierarchical arrangement is made by breaking it down into three elements: objectives, followed by variables, and sub-variables, which later can be changed or added as needed.

Comparisons of each variable are carried out based on the AHP criteria importance rating scale as in table 1. According to Saaty (1983) [14], for various types of problems, there is a scale of 19, which is the best scale for expressing an opinion. The table below contains values and definitions of qualitative opinions from the current comparison scale, which will become a reference for AHP:

Table 1. AHP Criteria Importance Rating Scale

\begin{tabular}{lc}
\hline \multicolumn{1}{c}{ Information } & Score \\
\hline The two elements are equally important & 1 \\
\hline One element is slightly more important than the other & 3 \\
\hline One element is more important than the other & 5 \\
\hline One element is more essential than any other & 7 \\
\hline One element is more important than any other & 9 \\
\hline The values between two adjacent consideration values & $2,4,6,8$ \\
\hline
\end{tabular}

Then the results of the comparison of interests obtained are used to determine which variables are most important to those not. After getting the value of each existing variable, the variables are sorted from the highest to the lowest. 
After the most critical variables are sorted, an assessment of the availability of the existing variable components is carried out at the research location. To assess the availability of components for security and safety aspects in this motorcycle parking area, there is a component availability scale divided into four assessment levels, as shown in table 2.

Table 2. Variable Component Availability Value Scale

\begin{tabular}{lc}
\hline \multicolumn{1}{c}{ Information } & Score \\
\hline Available and according to standards & 4 \\
\hline Available but according to standard & 3 \\
\hline Available and it is not following to standard & 2 \\
\hline Not available & 1 \\
\hline
\end{tabular}

The value of the criterion importance scale was obtained through the AHP method, then multiplied by the value scale for the availability of variable components. The total value of each variable from the multiplication results then determines the security and safety aspects assessment based on the rating scale in table 3. The assessment of the security and safety aspects is divided into seven levels.

Table 3. Security and Safety Aspect Assessment Scale

\begin{tabular}{|c|c|}
\hline Information & Score \\
\hline Perfect & $=4.00$ \\
\hline Very very good & $4.00>x \geq 3.50$ \\
\hline Very good & $3.50>x \geq 3.00$ \\
\hline Good & $3.00>x \geq 2.50$ \\
\hline Pretty good & $2.50>x \geq 2.00$ \\
\hline $\mathrm{Bad}$ & $2.00>x \geq 1.50$ \\
\hline Very bad & $1.50>x \geq 1.00$ \\
\hline
\end{tabular}

\section{$4 \quad$ Result and Discussion}

\subsection{Lighting}

Lighting is considered the most crucial security feature in parking facilities [15]. The analysis results were carried out using a lux meter measuring device and only the ramp directly at the research location. Vehicle exit areas meet the minimum light intensity standards according to the NPA and IESNA. While the rest, both motorbike parking areas, vehicle entrances, stairs, and lobbies, have not met the standards. Especially in the motorbike parking area, there are still some areas where the light is not bright enough even with no lighting. There are still many lights that are not functioning, and the placement of the lights is not entirely correct in their location, and there is still a lack of lights in this parking location.

Figure 1 is one of two of the several malfunctioning lights at this motorcycle parking location. There are still several delicate items whose light intensity has decreased and does not fulfill standards and even turns off, thus making many dark areas in this parking location. 


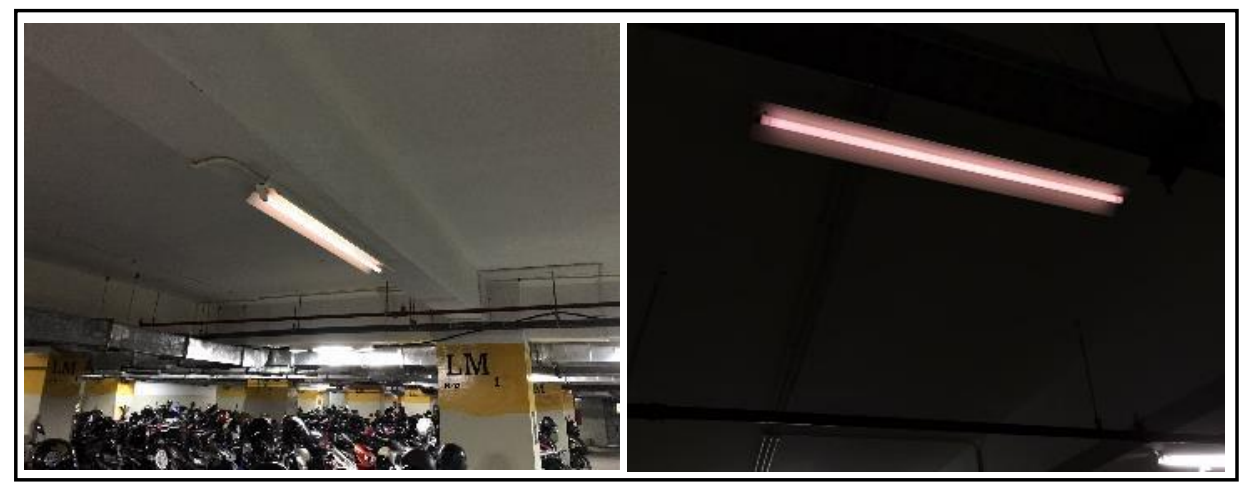

Figure 1. The Light Intensity of The Lamp has Decreased

The lighting in this parking area received a total score of 0.328 or very bad. Because there are still many lights that are no longer functioning in this parking area, either because they are dead or their intensity has decreased, it is necessary to carry out maintenance to repair and replace lights in the parking area.

To determine the type of lamp according to the BSN standard used as a reference for illuminating the parking lot, the Low-Pressure Sodium Gas Lamp (SOX) is used because in addition to being used for local roads and intersections. This lamp can also be used for rest areas, which are assumed to be similar to a parking lot.

\subsection{Security Management}

Security Management includes officers on duty in the parking area, both security officers and cleaners. Security management is also related to vehicles' entry and exit flow and how the payment system is.

Figure 2 explains the flow of vehicles in and out of the parking area, from entering the ramp-up to the parking ticket collection portal. Then take the parking ticket. After taking the parking ticket, go down to the parking area through the ramp, enter the parking area. This ramp is a ramp for exiting and entering the motorcycle parking area. Furthermore, after parking, exit using the same ramp as when you entered, then pay the parking fee at the payment post already available for three payment posts as shown in the image below. After paying the parking fee, go down through the same ramp as when entering the ticket collection area as shown in the image below and meet directly with Jalan Putri Hijau. 


\section{Management in and out of parking collection and payment}

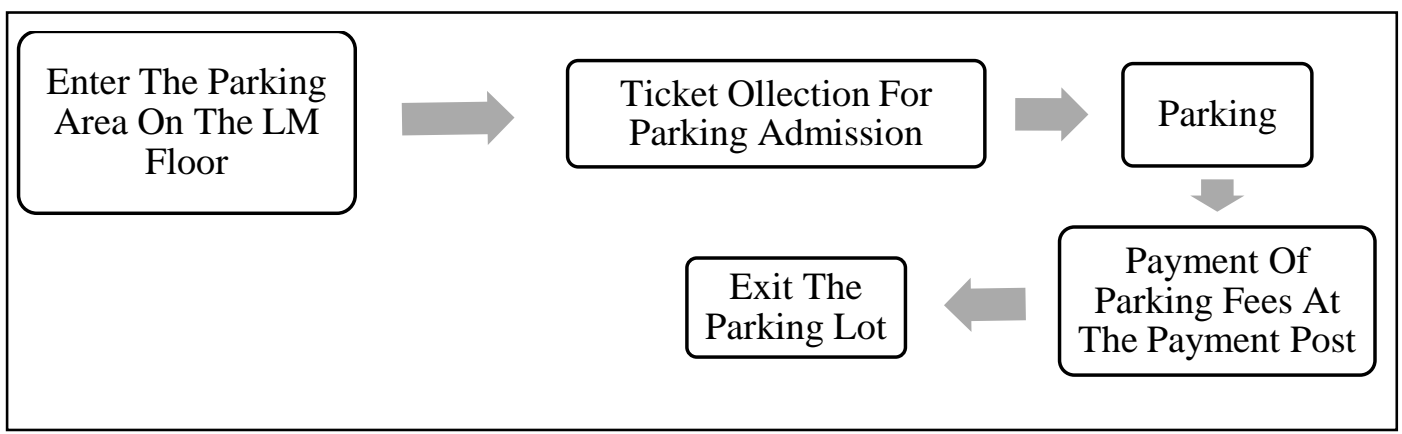

Figure 2. Parking Collection and Payment Exit Flow

For this variable, get a total value of 3,824 or fall into an excellent assessment category. This variable has reached the safety aspect with the CPTED concept. Access to and from the parking lot is at the same access point, thus making supervision of incoming vehicles better.

\section{Security guards on duty in the motorcycle parking area}

The number of officers stationed in this parking area is 4 to 5 people. These officers routinely go around checking security in the motorbike parking area, directing vehicles that enter the parking area, and even correcting the inappropriate position of the vehicle, as seen in figure 3 . These security guards are in the parking lot starting from this parking operation until closing hours.

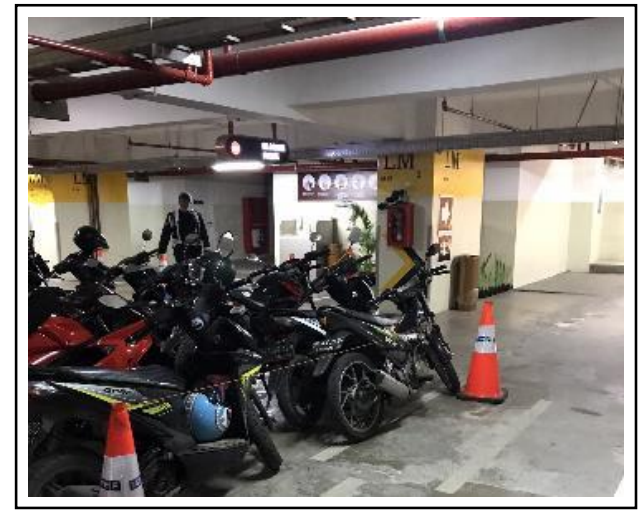

Figure 3. Security Officer on Patrol

This variable gets a total value of 3.78 , which means in the very, very good assessment category. This variable has reached the security aspect with the perfect CPTED concept. The officers are always in the parking area and routinely patrol to supervise incoming vehicles better so that drivers feel safe while in this parking location.

\section{Physical Maintenance}

In this motorbike parking area, routine cleaning maintenance is carried out. Cleanliness in this parking area is kept clean by cleaning officers, as seen in figure 4. This building is well maintained, starting from the condition of the wall paint that is still intact, the signs that are still 
in good condition; it is just that some parking markings have started to disappear or even do not exist. Likewise, with the lack of lighting in this parking area, there are still dark spaces in this parking area.

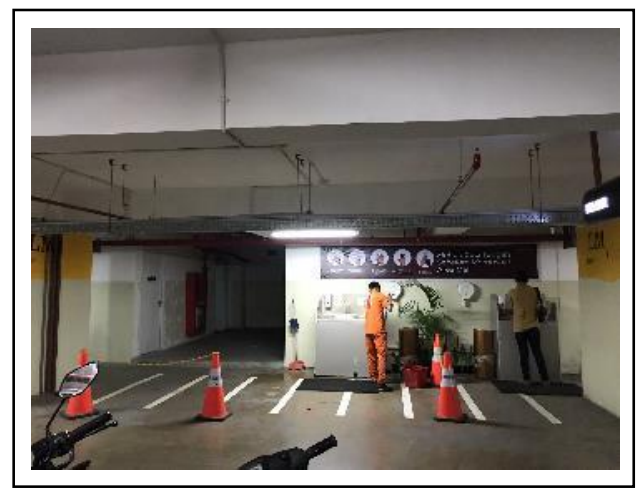

Figure 4. Cleaners On Duty

For this variable, it gets a total value of 3.78 , which means in the very, very good assessment category, where these results indicate that physical maintenance in this parking area has met the CPTED assessment and that the cleanliness of the parking area is maintained so that this location will feel comfort and safety. However, other physical maintenance needs to be improved, such as replacing dead light bulbs and repainting the missing parking markings.

\subsection{Boundary Control}

Boundary control is a limit in an area or a building that functions like access control and territorial affirmation. The purpose of limiting control on parking facilities is to block the access of undesirable parties to enter the area. Boundary control can also be a transition between areas in a building.

For this variable, get a total value of 3,616 or fall into an excellent assessment category. These results have shown that this variable has implemented the CPTED concept well, but some still need to be improved. The control restrictions on the parking area for vehicles are only limited by parking markings on the floor so that the parking situation at the location is a bit messy. For this reason, it is necessary to have an architectural boundary control in the form of an iron wheel stopper placed primarily in the opposite parking slot so that the existing parking at the research location is more orderly.

\subsection{CCTV and Surveillance}

\section{CCTV}

The mechanical surveillance equipment at the Podomoro Mall parking location is in surveillance cameras or CCTV as many as 5 CCTVs. However, this CCTV is only located in an open area, and it does not reach the hidden corner in this parking location. Because in this parking location, large structural columns are causing many blind spots in this parking area. 
This variable gets a total value of 2,716 , which means this variable is in the category of good assessment. This value shows that the application of the CPTED concept of the CCTV variable is good because CCTV almost covers the entire motorcycle parking area.

\section{View access to the parking area}

For this variable, it gets a total value of 0.034 or is in a terrible category. Applying the variable CPTED concept, the result of this value needs to be improved again to achieve security in this parking area. View access to this parking area is relatively limited due to a large number of columns in the structure and its size, which is quite large, up to $150 \mathrm{~cm}$. Since there are so many columns, there are many areas that are difficult to reach the eye. We can see the conditions in figure 5 .

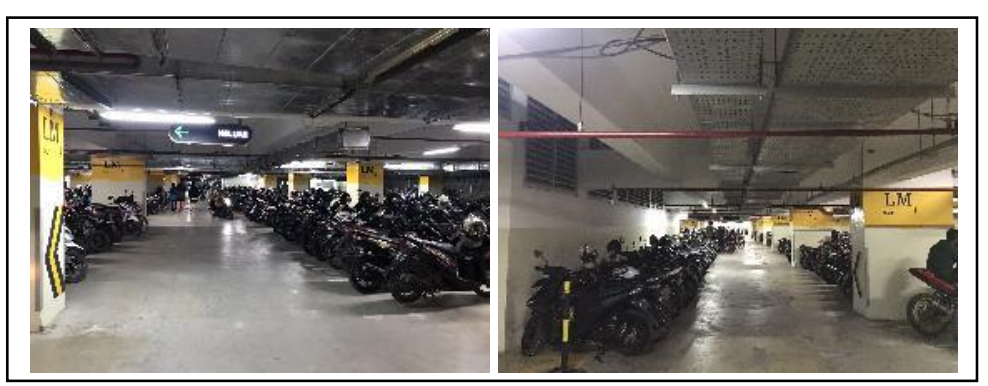

Figure 5. View Access to Parking Area

\subsection{Landscapes and Access Points}

\section{Location and number of access to motorbikes}

This variable gets a total value of 3,868 , which means this variable is in the perfect assessment category. The results of this value indicate that the application of the variable CPTED concept has been fulfilled.

\section{Position And Some Access For Pedestrians}

This variable gets a total value of 0.708 , which means it is in the terrible assessment category. This value shows that the application of the CPTED concept for this variable needs to be improved because access to pedestrians has so many options. Hence supervision is challenging to do well. There are seven emergency stairs in this parking area that pedestrians can access. 


\subsection{Vehicle/Human Parapet}

The size of the dividing wall in the parking area meets existing standards. The height of this dividing wall is $111.5 \mathrm{~cm}$, and the thickness is $15 \mathrm{~cm}$ and; the dividing wall on the ramp has a height of $110 \mathrm{~cm}$ with a thickness of $15 \mathrm{~cm}$. The condition looks solid for the dividing wall in this parking area, even though many of it has peeled off.

This variable gets a total score of 3.704 and 3.752, which means it is in the perfect assessment category. This value indicates that this variable has met the existing standards, as evidenced by the dimensions of the size of the parapet that is by the applicable standards.

\subsection{Floor Surface}

The irregular floor surface on the ramp gets a total value of 3.704, which means in the perfect assessment category. This value indicates that this variable has met the existing standards. The floor surface on the ramp uses a good finish, namely, rough concrete with a herringbone pattern finishing to prevent the vehicle from slipping when going up or down, as seen in figure 6 . The quality of the concrete cover is good enough so that it is not easily damaged and does not endanger the driver.

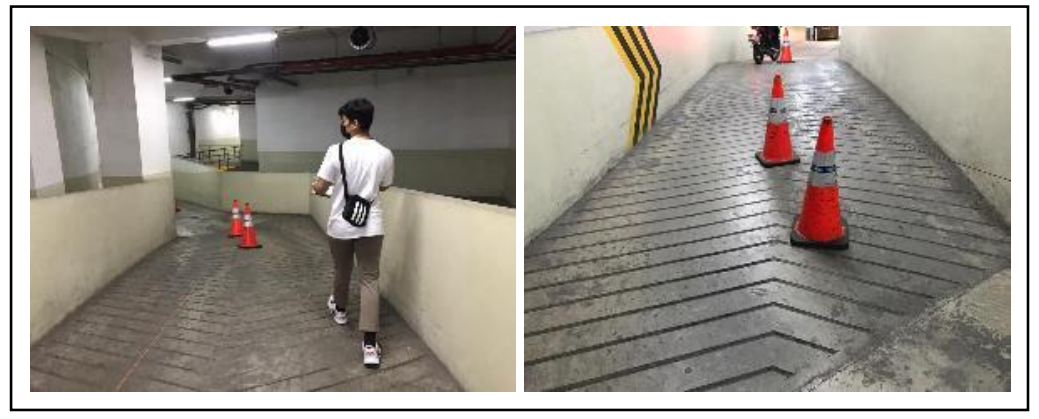

Figure 6. Ramp floor surface on Parking Area

The Floor Surface variable in the Parking Area gets a total value of 2.008, which means it is good enough. This value indicates that the variable Floor Surface in the Parking Area is sufficient. The floor surface in this parking area does not use light broomed finishing or swirl finishing, but only ordinary cement and many shallow cracks and holes, as seen in figure 7. However, the Podomoro City Mall parking area floor does not endanger users because the floor is not slippery, so it does not cause a slip hazard.

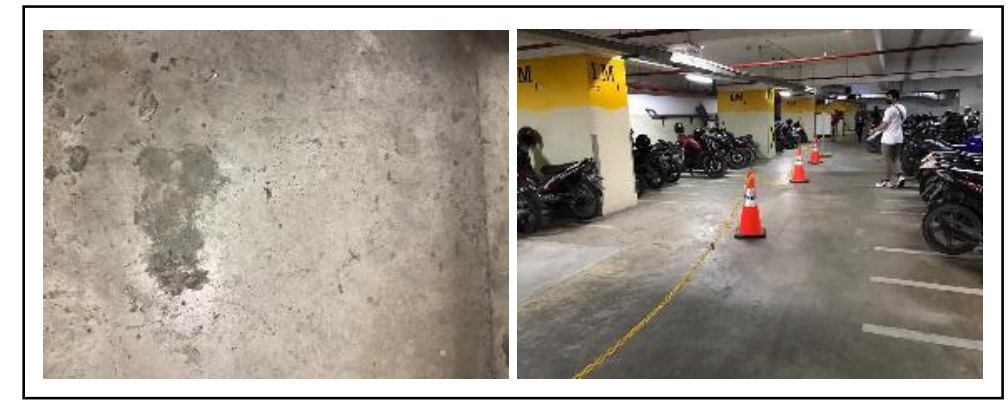

Figure 7. Parking Area Floor Surface 


\subsection{Vehicle Meeting with Pedestrians}

Because there are no pedestrians in this parking area, this variable gets a total value of 0.335 , which means it is in the terrible assessor category. This value indicates that the Vehicle Meeting with Pedestrians in the Parking Area variable does not meet the existing standards. There is no particular lane for pedestrians found in this motorcycle parking area, and the laying of roads for pedestrians in this parking building cannot be easily found. Easily found by pedestrians so that pedestrians are still crossing the vehicle lane.

\subsection{Drainage}

The Trench variable on the edge of the parking area floor in this parking area gets a total value of 1.164 , which means it is in the terrible rating category. This value indicates that this variable does not meet the CPTED concept. In this parking area, there was no edge drains on the floor of the motorcycle parking area. However, there was rarely stagnation of water. However, one ditch has been found in this parking floor area on the vehicle ramp, direct access to the Mall parking area. Even though the depth of the trench at the edge of this ramp is relatively shallow, it is sufficient to drain the rainwater that flows towards this ramp, as seen in figure 8 .
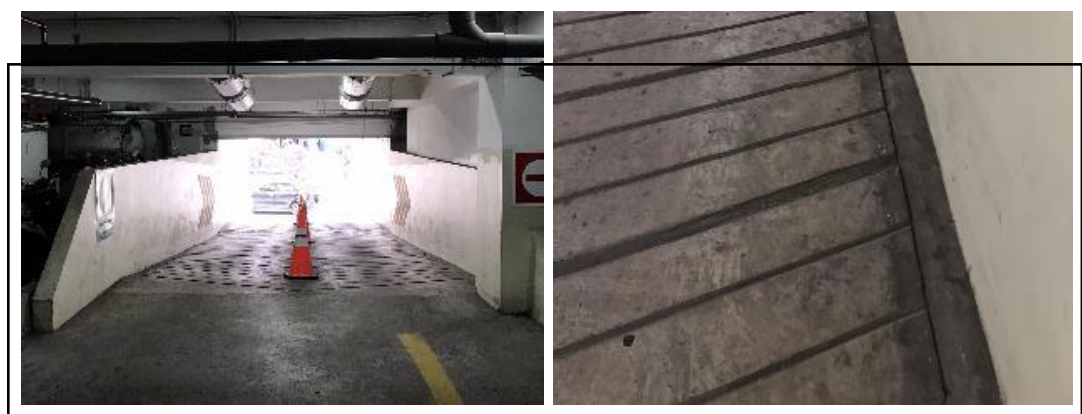

Figure 8. Trench on the Edge of the Ramp

The floor drain variable gets a total value of 1.16 , which means it is in the terrible rating category. This value indicates that this variable needs more attention. However, although there were not many floor drain points found in the motorbike parking area of this Mall, no puddles were found. The floor drain found was only a tiny hole that did not have an iron cover and the drain as seen in figure 9.

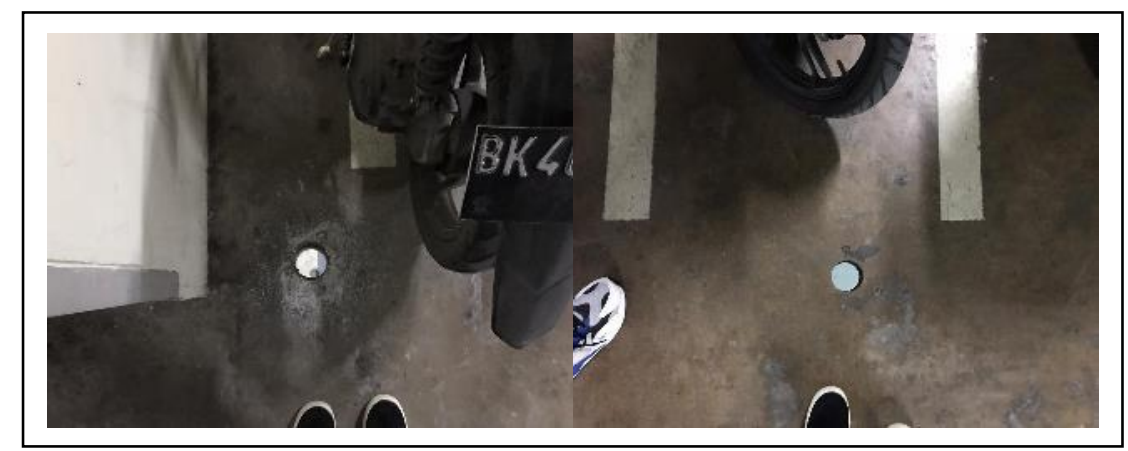

Figure 9. Floor Drain Point in the Parking Area 
There is no trench with an iron cover at the entrance and exit of the Podomoro City Mall motorcycle parking area. So that for the Trench variable with an iron cover at each point of entry and exit of the vehicle in the parking area, it gets a total value of 0.342 or is included in the terrible rating category. This value indicates that this variable needs more attention. To handle this, it is necessary to build a trench with an iron cover at each point of entry/exit of the vehicle at the lowest point.

The variable with no standing water in the parking area gets a total value of 3,768 , which means it is in the perfect assessment category. This value indicates that this variable has implemented an excellent CPTED concept. In the Podomoro parking area, puddles are very rare. There is almost no standing water that could endanger the driver even though the provision of trenches and floor drain in The motorcycle parking area is minimal.

\section{Conclusion}

For motorbike parking capacity, there are 786 parking slots in this parking lot. The motorcycle parking lot is only on this one floor, namely the Lower Mezz P2 floor.

This parking area is used for visitors and also workers who work in this mall. However, the parking area is no longer the one in the design. Several parking slots are not used and have been converted into lanes for circulation.

The results of the study of the application of the CPTED concept theory for security aspects and safety aspects in the Podomoro Mall motorcycle parking area show that there are elements of the CPTED concept and safety aspects that have not been fully applied to this motorcycle parking area. However, overall, security and safety in this parking area are guaranteed because almost all the variables examined at this location have met the existing standards, and the drivers also feel safe and secure while in this parking area even though some aspects are not fulfilled but if can be improved will be much better.

\section{REFERENCES}

[1] F. L. Rahmawati, "UNDANG-UNDANG REPUBLIK INDONESIA NOMOR 22 TAHUN 2009 TENTANG LALU LINTAS DAN ANGKUTAN JALAN," vol. 2, no. 5, p. 255, 2009.

[2] Kementrian Perhubungan, "Pedoman Perencanaan dan Pengoperasian Fasilitas Parkir." p. 204, 1998.

[3] T. D. Crowe and L. Fennelly, "Crime Prevention Through Environmental Design," Crime Prev. Through Environ. Des., pp. 1-360, 2013, doi: 10.1016/C2012-0-03280-2.

[4] M. Hedayati Marzbali, A. Abdullah, and M. J. Maghsoodi Tilaki, "The effectiveness of interventions in the built environment for improving health by addressing fear of crime," Int. J. Law, Crime Justice, vol. 45, no. 203, pp. 120-140, 2016, doi: 10.1016/j.ijlcj.2015.12.002.

[5] T. Ha, G. S. Oh, and H. H. Park, "Comparative analysis of Defensible Space in CPTED housing and non-CPTED housing," Int. J. Law, Crime Justice, vol. 43, no. 4, pp. 496511, 2015, doi: 10.1016/j.ijlcj.2014.11.005. 
[6] N. K. Katyal, "Architecture as crime control," Yale Law J., vol. 111, no. 5, pp. 10391138, 2002, doi: 10.2307/797618.

[7] P. M. Cozens, G. Saville, and D. Hillier, "Crime prevention through environmental design (CPTED): A review and modern bibliography," Prop. Manag., vol. 23, no. 5, pp. 328-356, 2005, doi: 10.1108/02637470510631483.

[8] R. I. Atlas, S. L. Sorensen, and J. G. Hayes, "21st Century Security and CPTED: Designing for Critical Infrastructure Protection and Crime Prevention, Second Edition," 21st Century Secur. CPTED Des. Crit. Infrastruct. Prot. Crime Prev. Second Ed., pp. 5990, 2013, doi: 10.1201/b15046.

[9] C.-H. Tseng, J. Duane, and F. Hadipriono, "Performance of Campus Parking Garages in Preventing Crime," J. Perform. Constr. Facil., vol. 18, no. 1, pp. 21-28, 2004, doi: 10.1061/(asce)0887-3828(2004)18:1(21).

[10] M. S. Smith and Office of Justice Programs, "Crime Prevention Through Environmental Design in Parking Facilities," Res. Br., p. 12 pages, 1996.

[11] A. P. Chrest, M. S. Smith, S. Bhuyan, M. Iqbal, and D. R. Monahan, Parking Structures. 2001.

[12] I. INTERNATIONAL CODE COUNCIL, International Building Code Errata. 2006.

[13] Essex Council, "Essex County Council - Parking Standards Inc dimensions," no. September, 2009.

[14] T. L. Saaty, "THE ANALYTIC HIERARCHY PROCESS: DECISION MAKING IN COMPLEX ENVIRONMENTS," pp. 285-286, 1984.

[15] P. Cozens, "Crime prevention through environmental design in Western Australia: Planning for sustainable urban futures," Int. J. Sustain. Dev. Plan., vol. 3, no. 3, pp. 272292, 2008, doi: 10.2495/SDP-V3-N3-272-292. 